\title{
The role of Personal Development Planning (PDP) for employer sponsored students - an exploration of how PDP learning activities can support CPD and workforce development requirements
}

\author{
Julie Savory \\ University of Salford, UK \\ Carole Conroy \\ University of Salford, UK \\ Donna Berwick \\ University of Salford, UK
}

\begin{abstract}
Over the past decade government policy has emphasised the need for effective and active partnerships between employers and higher education providers (DfES, 2003; Wedgewood, 2007; CBI, 2008; BIS, 2009) to meet the requirements of a globalised knowledge economy. This paper discusses the findings from a research project undertaken at the University of Salford which sought to explore how:
\end{abstract}

- Personal Development Planning (PDP) input can support the development of employability skills for part-time sponsored students.

- Employer engagement could be drawn upon to enhance such provision.

Informed by the Appreciative Inquiry approach (Cooperrider 1986, cited Reed, 2007), the methodology included a questionnaire survey of two student cohorts and thirteen semistructured interviews with organisational development managers from sponsoring organisations to explore perceptions of the value of PDP within day release provision and potential benefits to the organisation. A follow up focus group with employers explored further staff development needs and the potential for PDP processes within Higher Education (HE) courses to complement their existing Continuing Professional Development (CPD) and in-house staff and workforce development strategies. 
The paper concludes that dialogue between academic staff, students and sponsoring employers is valuable in developing shared understandings of the role of PDP activities within $\mathrm{HE}$ curriculum, the potential benefits for individual professional development and the workforce development requirements of organisations. Employers participating in the research stressed the importance of 'functioning knowledge' (Biggs 2003, cited Walsh, 2008) and discussions highlighted the potential for PDP to provide a bridge between the discipline specific knowledge which forms the main focus of HE courses and the transdisciplinary knowledge produced by the largely informal learning that occurs during the course of professional practice (Gibbons et al., 1964). The joint dialogue enabled exploration of perceptions of the difference between CPD and PDP and identification of how links between PDP and appraisal processes in the workplace could be strengthened, including suggestions for practical activities which could be incorporated into HE programmes and employers' performance review processes.

Key words: Personal Development Planning (PDP); Continuous Professional Development (CPD); workforce development; functioning knowledge; mode 2 knowledge; Appreciative Inquiry.

\section{Introduction}

Traditionally Higher Education (HE) provision has focused on the production and transmission of academic knowledge linked to specific subject disciplines. Such knowledge was designated Mode 1 knowledge by Gibbons et al in 1994, who proposed that in a modern knowledge economy, a different but no less valid type of knowledge (Mode 2) is produced outside universities when theoretical discipline specific (Mode 1) knowledge is applied in the workplace. Gibbons et al. (1994, p.33) proposed that this Mode 2 knowledge supplements Mode 1 knowledge but is also different in that it has the potential to be trans-disciplinary, being 'produced in the context of application'. Biggs (2003 cited Walsh, 2008) argues that effective learning for the workplace requires the development of 'functioning knowledge', which consists of declarative knowledge (theoretical), procedural knowledge (the skills to apply knowledge) and conditional knowledge (awareness of appropriate circumstances in which to apply the declarative and procedural knowledge). Similarly, Knight and Yorke (2004) and Yorke and Harvey (2005) suggest that employability is a complex construct consisting of a combination of 
Understanding, Skilful practices, Efficacy beliefs and Meta-cognition (USEM). In a rapidly changing economy and society, trans-disciplinary knowledge (Egan, 2004) and 'generative learning' to enhance creativity (Senge,1990, p.14) are increasingly important to enable organisations to tackle complex, multi-dimensional and frequently unpredictable issues, and adapt swiftly to meet new challenges and opportunities to remain competitive with regard to both product provision and customer service (Harrison, 2005).

During the past decade, understandings of what a university education should entail have moved from a traditionalist approach of induction into an academic discipline, to a combination of enterprise and progressive understandings (Trowler, 2006). These respectively emphasise preparation for work and the development of the individual (Trowler, 2006). By 2005/6 a sector-wide agreement sought to encourage all Higher Education Institutions (HEIs) to provide structured and supported opportunities for students to engage in Personal Development Planning (PDP) (QAA, 2001).The main driver of this was the recommendation of the National Committee of Inquiry into Higher Education (Dearing, 1997) that students need to be able to plan and review to continually enhance their learning and articulate the knowledge, skills and competencies they have gained from their HE experience to convince future employers of their employability.

\section{Discussion of the literature}

The main emphasis of existing literature on employers, PDP and employability skills is on the long reiterated concern that traditional undergraduates are not able to articulate the skills and attributes they have developed whilst studying for a degree and/or are unable to demonstrate capability in the key graduate attributes sought by employers (Edwards, 2005; Little et al., 2005; Yorke, 2009). Literature on employees undertaking higher level learning concentrates on the emerging trend towards work-based learning and the pedagogies required (HEA, 2008). The literature has not yet explored the needs of sponsored students on day release programmes and their employers.

Workforce development consists of activities which increase the capacity of individuals to participate effectively in the workplace, thereby improving their productivity and employability (DfES, 2003). Harrison (2005) contends that the emergence of a new knowledge economy in which the application of knowledge adds more value to the 
organisation than more traditional factors, for example, labour, has implications for organisational development. Organisations wishing to succeed need to develop workforce capability so that learning enables the application of new knowledge to continuous improvement and innovation.

Research (CIPD, 2001) suggests that people are motivated when they have the necessary knowledge and skills to perform well and when they are given the opportunity to use their skills in their jobs. Furthermore, Soltani et al. (2004) conclude that the main purpose of Human Resource (HR) performance evaluation in a quality-focused organisation should be to help employees to improve their performance rather than performance control. As part of the performance management cycle, a broad ranging appraisal discussion which aims to motivate appraisees should emphasise future oriented action planning and continuing development. This triggers a process of PDP, action and review (Harrison 2005).

Increasingly importance is placed by professional bodies upon the need for their members to engage in reflective activities as part of their CPD (including the Chartered Institute of Housing and the Institution of Occupational Safety and Health). In 2004, Egan concluded that discrete professional and occupational technical skills and knowledge training would not be enough to generate the trans-disciplinary knowledge, understanding and skills required to create a joined up approach to tackling the complex, multi-dimensional and frequently unpredictable issues found in planning, maintaining and managing sustainable environments and communities. Subsequently, the Academy for Sustainable Communities $(2007 ; 2008)$ asserted that professionals, in addition to being able to understand how their day-to-day activities contribute to the broader agenda and keeping abreast of new knowledge, need to be willing to try out new ways of working and to operate within a values framework which enables them to assess the implications of how they deploy their skills and knowledge, and to justify the decisions that they make.

\section{The research context}

The research project was undertaken at the University of Salford as part of the National Action Research Network on Researching and Evaluating Personal Development Planning and e-Portfolio Practice (Peters et al., 2009). In the academic year 2004/05, PDP learning activities had been embedded within an accredited academic learning skills module in the 
undergraduate Housing Practice course undertaken by part-time employer-sponsored students. The PDP provision includes a student PDP handbook with prompts to facilitate reflection on progress in academic skills and career development; progress reviews with a personal tutor; reflective commentaries on progress and development of academic and professional skills. In 2005/06, an evaluation was undertaken to establish if, when compared to extra-curricular approaches, embedding PDP within an accredited module resulted in better engagement with the process. Fifteen Housing Practice students participated in two focus groups in which a recurring theme was that the PDP support materials need to be tailored to meet the needs of different types of student cohort. However, the majority had valued support provided by a personal tutor with thirteen positive comments on the value of such support for confidence building, discussing assignment feedback, and for planning and setting targets (Savory, 2008). Subsequent end of module evaluations have found over $50 \%$ of students continuing to question the relevance of the PDP learning activities for part-time mature employer-sponsored students. Student concerns are that some elements 'are irrelevant for students who already work in their chosen career' and that it 'duplicates reviews in the workplace' and 'takes up time that could be used on core subjects. In contrast, in July 2010 the professional practitioner external examiner for the Foundation Degree in Housing Practice commented in his annual report that 'I consider the programme to be well designed, reflecting a diverse range of housing and housing-related material but also focusing, through group work and reflective assignments, the opportunity for self-development. This holistic approach to housing, within a wider social, regeneration and political context, is essential'.

The research project sought to build upon existing positives in provision by engaging with sponsoring employers to establish their views on the value of the inclusion of PDP learning activities in helping to meet their staff development requirements. It is anticipated that increased recognition by sponsoring employers will increase the perceived value of such activities with students.

\section{Methodology}

The framework for the research was informed by the Appreciative Inquiry (AI) methodology (Cooperrider 1986, cited Reed, 2007). Rather than focusing on a problem-solving 
approach to what doesn't work, the Al approach seeks to identify, from the perspective of different stakeholders, what aspects of a situation work well and to explore how these can be built upon to enhance existing approaches (Cooperrider and Whitney, 2005). Hence it has an emphasis on developing positive relationships between different stakeholders (Cousin, 2008).

An Al approach involves working through the four Ds of Discovery, Dream, Design and Delivery (Cooperrider and Whitney, 2005). This research project covered the first two stages. The discovery stage involved identifying what aspects of current activities and materials to support PDP were felt to be of value by students and their sponsoring employers. Building on comments made by students in the discovery stage, the dream stage concentrated on seeking to develop a shared vision with sponsoring employers about how PDP activities could be effectively developed to help meet anticipated staff development outcomes (Lewis et al., 2008).

At the discovery stage, a structured questionnaire was administered to two 2008/09 cohorts of students. One cohort was in the second year of the Foundation Degree in Housing Practice, the other was studying for a MSc in Occupational Safety and Health $(\mathrm{OSH})$. The questionnaire sought to seek views on the links between their Continuing Professional Development (CPD) needs and the PDP activities included within their course. Seventeen out of thirty questionnaires were returned by the Foundation Degree in Housing Practice students and five out of thirteen questionnaires were returned by the MSc in OSH students. The questionnaire was administered towards the end of the academic year and response rates were affected by difficulties in following up nonresponses from students who had little physical contact with the university during the vacation period. Response rates may also have been affected by a lack of engagement with the existing PDP provision. The questionnaire included a combination of questions which required a yes/no answer and open-ended questions to generate qualitative data, providing deeper insight into perceptions.

In addition thirteen semi-structured interviews were undertaken with sponsoring employers with a view to finding out what staff development outcomes were sought, if they were aware of the PDP input on the programmes their employees were undertaking, and if they felt it was of value. Ten were from sponsoring social housing organisations, of which four were line mangers with operational responsibility for delivery of housing services and six 
were organisational development managers with responsibility for ensuring appropriate staff development provision is in place to meet the requirements of the organisation. Three representatives from organisations sponsoring students on the MSc were interviewed. They were all operational managers responsible for health and safety issues in local government or the NHS.

The student questionnaire and the semi-structured interview schedule for sponsoring employers were informed by findings from the literature review, from issues raised in a previous evaluation of PDP provision (Savory, 2008), and insights into employer concerns drawn from the researchers' experience of liaising with sponsoring employers as programme leaders. The interview schedule for sponsoring employers was piloted with an employer representative and minor adjustments to question phrasing made. The student questionnaire was piloted with a colleague in the Student Support Service but timing constraints prohibited piloting it with students. Deeper insights into student perceptions would have been gained through interviews or focus groups but this option was ruled out due to constraints of the academic year and practical difficulties of bringing together students from a large regional catchment area who only attended the university one day per week.

To facilitate further exploration of employers' views and to begin engaging in a process of 'sense making' and developing shared understandings, as well as starting to identify practical suggestions for developing current practice, a follow-up focus group session was held with five sponsoring employer representatives. The activities and discussion prompts used were informed by an initial review of the data collected from the employer interviews and student questionnaire. Reflection in action within the focus group enabled discussion prompts to be adjusted to respond to points being raised. This resulted in participants being asked to brainstorm and rank the top six competencies they sought from employees, helping to focus discussion on how PDP activities could support the development of the competencies.

Following transcription, qualitative and quantitative responses from the questionnaire, interviews and focus group were analysed for themes. These are summarised in the following section. 


\section{Findings}

To show the progression through the Al framework, the findings will be presented using the discovery and dream stages of the Al framework.

\section{Discovery}

\section{Student views}

The analysis of the student questionnaires found that increased knowledge and confidence in dealing with service users, peers and managers, plus potential for career enhancement, were the main goals for students taking the courses. All respondents felt they had developed a greater understanding of subject knowledge which in turn had increased their confidence, with seven of the foundation degree students having changed their job role whilst on the course. Fifteen commented that their understanding of their role within their organisation and the role of their organisation in a wider context had been increased. Unexpected gains identified by students were building self-esteem and, for some, mapping where they are and planning for achievement of further ambitions.

When asked about the overall value of the PDP process, on a Likert scale of one to ten (one is very useful and ten useless), the majority of responses for both cohorts fell in the lower intervals between six and eight, with just one undergraduate student finding the process very useful. A common theme illustrated by this quote is that 'it is not very useful as unable to implement the aims and objectives with my employment, as PDPs are not regular and not linked... if it was, I would definitely benefit from this more'. Another student commented 'I currently don't have a PDP action plan so unable to use a lot of skills from the course and put knowledge into practice'. Five positive comments were made regarding the value of the process all of which indicated that for some students it had enabled them to make changes and transfer learning to other situations - 'this has enabled me to reflect on my ways of working and how I can improve this...I apply experiences to other situations which has assisted my development'.

There was limited identification of links between workplace CPD and appraisal processes and PDP undertaken as part of the university course. Comments included 'I've never been asked about it at work' and 'some issues are mirrored, some not'. PDP on the course was seen as focusing on transferable personal skills and competencies whereas CPD in the 
workplace was felt to have more of a focus on professional practice and training. Where links were identified, they were more about practical issues such as not having to attend other courses, availability of study leave and payment of university expenses. A strong theme was that the process of developing applied practical skills, such as oral and written communication and ICT, which could then be transferred to the workplace, was the best way of supporting their personal and professional development. One student commented that the practical approach suited her style of learning.

With regard to the value of PDP activities and resources in supporting work related CPD requirements, the following feedback was received. Twelve of the undergraduate students valued the support provided by a personal tutor which was felt to build confidence, provide reassurance and an opportunity to clarify issues about the course, and seek advice and guidance, in some cases about career development. One student felt such support could be enhanced by linking it to an action plan agreed by tutor, student and employer. Only a very small minority of students (three of the undergraduate respondents) felt the student PDP diary supported their work-related CPD, commenting that it helped to develop reflective skills and was useful for recording achievements. The majority did not make use of it as it was not a formal course requirement. Suggestions for making it more beneficial were closer content link with sponsoring employers' PDP documents, making it paperless and accessible through the virtual learning environment (VLE), and using it in meetings with a personal tutor to review progress.

Writing reflective commentaries was viewed as useful by four out of five of the postgraduate students and nine out of seventeen of the undergraduate students. The postgraduate students were fairly pragmatic, clearly identifying a link with the requirements of the professional body. Positive statements from the undergraduate students included 'makes me think back to what went well, what didn't, what and how things could be improved', with one student suggesting the potential for links with their workplace personal development review.

\section{Sponsoring employers' views}

The semi-structured interviews with employer representatives explored

- $\quad$ The rationale for sponsoring students. 
- Whether the anticipated staff development outcomes were being achieved.

- Employer awareness of PDP input on courses.

- Employer views on its value.

All thirteen employers interviewed identified the workplace appraisal or Personal Development Review (PDR) process as the means by which decisions to send students on sponsored day release courses were made. The reasons for sponsoring students were varied with some interviewees emphasising the importance of subject and technical knowledge, others emphasising organisational needs such as reputation, staff retention and meeting business strategy to provide excellent services, and others more concerned with competencies and behaviours. A common theme was the need for organisational benefits as well as individual staff development.

All employer respondents initially stressed the importance of subject and technical knowledge and the ability to 'step back' and see 'the bigger picture'. This could be equated with the Mode 1 knowledge which Gibbons et al. (1964) proposed was the traditional form of knowledge created with HE. However, when probed further, respondents commented on the need to meet the business strategy and provide continuously improving services, with seven noting that this in addition required a focus on competencies and behaviours and an ability to apply knowledge in a skilful way appropriate to the circumstances. One respondent commented it is 'not just housing law, it's how you deal with that difficult customer without creating more issues from it...they need to be able to think about what their impact would be in a real life situation'. Another stated 'for me, it is not just the technical knowledge....it's the core fundamentals I'm interested in: how to work as a team, how to communicate within a team, how to respect everybody, are they creative, can they think of new ways of doing things'. Similar comments included:

It is important to be able to use knowledge to shape how they manage and perform on a day to day basis.

Advanced problem-solving and analytical skills were identified as important:

They need to be able to think...to deal with 'messy' housing management issues. 
[They need] confidence, self-awareness and enhanced knowledge to be able to respond appropriately in residents' meetings or business meetings where they could be put on the spot by other agencies or senior managers.

Enhanced communication and interpersonal skills and an ability to transfer knowledge and learning to the workplace.

[To be able] to think what am I doing, why am I doing it, what have I got from it, how am I going to use it?

To be able to engage with the profession at a higher level than before.

These comments link with the concept of Mode 2 knowledge which, according to Gibbons et al. (1994), is developed from the skilful application of Mode 1 knowledge; the concept of 'functioning knowledge' put forward by Biggs in 2003; and with Knight and Yorke's (2004) USEM framework for understanding the complexity of employability.

Generally all respondents felt that the staff development outcomes were being met, as the sponsored students were able to independently manage projects, take on more responsibility, engage at a different level, and progress within the organisation. The established reputation of the university for professionally accredited provision was identified, with eight of the respondents indicating scope for further development of the dialogue between the university and sponsoring employers to provide better connection between sponsored employees' studies and the workplace. One organisational development manager commented 'there can be a lack of knowledge on part of the employer about what sponsored students are studying... and this means that the line manager won't utilise the knowledge and skills developed'. Another commented 'we are not very good internally at following up learning being undertaken by sponsored employees...we need to be thinking about asking them how they are going to do things differently'.

None of the respondents were aware of the PDP element of the courses, however, all bar one respondent thought that activities supporting the PDP process had the potential to be useful or extremely useful. There was general agreement that there was scope for PDP provision to support appraisals and PDRs in the workplace and that it could support the 
good practice of a learning organisation (Senge, 1990) and the achievement of organisational goals. Comments included:

Useful for encouraging reflection and taking stock...a great way to embed learning into the workplace.

If a career development plan could be agreed through their academic work it could provide a kind of bridge.

Two line managers felt that the PDP support materials provided by the university could be used by themselves as managers to provide more focused support for the students they sponsor and gain more insight into their ongoing progress on the course.

\section{Focus group findings}

Five employers from the social rented housing sector attended the two and a half hour focus group session (three operational managers and two organisational development managers). Themes resulting from the interviews were reiterated. The first activity which required participants to define and differentiate between PDP and CPD revealed an initial lack of clarity about the difference. Following discussion, a consensus was reached that PDP is about personal ownership of ones own learning and development with the focus on 'how' the employee works. In contrast, CPD focuses on 'what' role the employee has and the training, knowledge, and qualifications required to undertake the role and maintain professional currency. The ensuing discussion confirmed that sponsoring employers often have little knowledge of the learning activities their sponsored employees are engaged in. There was a perception that CPD provision is often rather ad hoc but with an increasing trend to link CPD with performance management.

A further exercise encouraged participants to explore CPD from the perspective of a student being sponsored to undertake an HE course. Participants identified that to optimise the benefits there would need to be shared understanding and clarity about the roles and responsibilities of the employee and employer, and support to enable both parties to see the benefits for the organisation and personal development of the employee. In a discussion of how employers could facilitate staff optimising the benefits from CPD activities, it was felt that there needed to be discussion of CPD at regular performance 
reviews with a focus on 'what have I learnt not what have I done' - a discussion about how academic learning will impact on and influence working practices rather than a tick list of different topics studied. There was recognition that sponsored employees will want help to make the link between theory and practice and that reflection would help build confidence and a recognition of 'distance travelled' on the part of the employee by both employee and employer.

\section{Dream stage}

To start to identify how to build upon existing practice in personal and professional development, the focus group participants identified and prioritised the top six core competencies they required in employees. These were: communication;

influencing/negotiation; team working; assertiveness; sensitivity/emotional intelligence and an ability to self-manage and act autonomously. In addition to practical opportunities to develop competencies, such as participating in group work, debates, mock interviews and delivering oral presentations, a number of suggestions for enhancing reflective learning activities and assessments were suggested:

- Module assessment could include a section requiring students to identify what they will take back to the workplace to share with colleagues or to influence or change their own practice.

- Students could write a reflective report, as if for their sponsoring employer, as an assignment, or could be asked to identify points from their reflection which they would like to share with their employer. Prompts for the reflective commentary would be: what have you learnt? How may you use it in the workplace and what support may you need to do so?

- As an exercise students could be required to identify a workplace situation where they had to influence or negotiate or give a difficult message, and reflect on how they did it, what went well and what didn't.

- Students examine the core competencies sought by their sponsoring organisation and reflect on their strengths and identify actions they could take to strengthen their performance in competencies in which they felt less strong.

- Students examine filmed scenarios and discuss 'why has someone done this?' to help develop an ability to see other dimensions and perspectives on an issue. 
The focus group participants also identified that their own practices with regard to support and performance review processes could be enhanced to maximise the benefits for the organisation and sponsored students. There was discussion about providing more support over and above funding and time off work and of the need for strengthening of links between employer review processes and students' reflection and engagement in a process of PDP. A key moment was when one participant stated that she would be changing practice in forthcoming PDRs to include a discussion, not just of what topics had been studied but also to ask 'what have you learnt and how will it impact on your practice?'.

Amongst the employer participants in the focus group there was a general view that engaging in a dialogue with course tutors had been very valuable in helping develop a shared understanding of what outcomes were sought from sponsored study and how employers and the course team could work together to support students' achievement.

\section{Discussion and conclusion}

The research project sought to explore how PDP input can support sponsored students' CPD and the staff development requirements of their employers. The findings indicate that sponsoring employers place considerable emphasis on subject and technical knowledge but at the same time refer to the need for students to be able to problem solve and act autonomously in unpredictable complex situations, in line with the concept of functioning knowledge (Biggs, 2003). All the employers taking part in the study felt that employees undertaking sponsored study engaged at a higher level with the profession and undertook enhanced roles and responsibilities in the workplace. However, the findings suggest that little thought had previously been given by employers to how they could ensure that sponsoring employees on the chosen programme of study would help meet their workforce development requirements. Prior to taking part in the research, there was a lack of awareness of the existence of PDP learning activities within the curriculum with a 'knowledge transmission' view of higher education prevailing. Following discussion with programme leaders through the interviews and focus group activities, there was a general endorsement of the potential of PDP activities to be extremely useful and help provide a bridge between theory and practice. It was perceived that the greater self-awareness that engagement in reflection generates, especially when linked to a PDP process of review, 
reflect and identification of actions to enhance or adapt practice, can help to establish an approach to professional and work-based practice development that mutually benefits the individual employee and the sponsoring organisation.

Engagement in a dialogue between the programme leaders undertaking the research and sponsoring employers was catalytic in developing increased insight and suggestions for improving practice for both parties. For the employers taking part, increased understanding of the inclusion of PDP activities led to discussion and the generation of ideas of how aligning these activities with their own appraisal and PDR processes could result in added value for the organisation being gained from their investment in employees' CPD. For the programme leaders, better understanding of sponsoring employers' priorities, for example, with regard to the key competencies, will inform future curriculum development and strengthen the guidance they are able to provide to sponsored students about how engaging with PDP processes can lead to more effective use in the workplace of the knowledge and skills gained on the course. The joint discussion also helped to identify practical suggestions for learning activities which could facilitate better linkage between the HE provider, the sponsoring employer and the employee. A future evaluation of the impact of introducing such activities would help to evidence the potential of PDP processes to provide a bridge between traditional Mode 1 knowledge and the functioning knowledge required in the workplace.

Maintaining ongoing dialogue with sponsoring employers through the establishment of a regular liaison forum will help to develop and nurture the suggestions made for closer linkage between programme PDP and organisations' CPD processes. Opportunities for the student voice to feed into these discussions should be included. Future developments could include development of e-Portfolio resources accessible through a virtual learning environment which sponsored students could adapt to meet the requirements of their academic course and to feed into workplace appraisal and PDR processes. This would help to overcome the concern raised by students that there was little identification of links between their workplace CPD and PDP undertaken as part of the HE studies. Similarly, three-way learning agreements established at the start of a course between sponsored employee, employer and programme tutors could help to increase shared understandings and clarity about how each party can contribute to ensuring knowledge gained will enhance the functioning knowledge required for successful organisational performance. 
An overarching conclusion is that providing opportunities for a joint dialogue between employers and HE providers is very valuable in developing shared understandings of the outcomes sought by employers from sponsored study and in identifying opportunities for greater collaboration to ensure that the added value potential in terms of enhancing functional knowledge to improve organisational performance can be achieved.

\section{Acknowledgement}

This paper is an outcome of the National Action Research Network on researching and evaluating Personal Development Planning and e-Portfolio practice project (2007-2010). The project was led by the University of Bolton in association with the University of Worcester and Centre for Recording Achievement, and in national collaboration with the University of Bedfordshire, Bournemouth University and University of Bradford. The project was funded by the Higher Education Academy, National Teaching Fellowship Project strand. More details about the project can be found at:

http://www.recordingachievement.org/research/narn-tree.html.

\section{References}

Academy for Sustainable Communities (2007) Mind the skills gap. Available at: http://www.ascskills.org.uk/pages/research/mind-the-skills-gap (Accessed: 11 May 2009).

Academy for Sustainable Communities (2008) A values framework for sustainable Communities. Leeds : Academy for Sustainable Communities.

Biggs, J. (2003) Teaching for quality learning at university. Maidenhead: Society for Research into Higher Education and Open University Press.

BIS (2009) Higher ambitions: the future of universities in a knowledge economy. Available at: http://bis.gov.uk/wp-content/uploads/publications/Higher-Ambitions-Summary.pdf (Accessed: 7 January 2010). 
CBI (2008) Stepping higher: workforce development through employer-higher education partnerships. Available at: http://www.cbi.org.uk/pdf/cbi-SteppingHigher.pdf (Accessed: 12 May 2009).

CIPD (2001) The change agenda: performance through people - the new people management. London: CIPD.

Cooperrider, D.L. and Whitney, D. (2005) Appreciative Inquiry: a positive revolution in change. San Francisco,CA: Berrett-Kohler Publishers.

Cousin, G (2008) Researching Learning in Higher Education. London:Routledge.

Dearing, R. (1997) National Committee of Inquiry into Higher Education. Available at: http://www.leeds.ac.uk/educol/ncihel (Accessed : 30 November 2008).

Department for Education and Skills (DfES) (2003) 21st century skills. Realising our potential: individuals, employers, nation. London: HMSO. Available at: http://www.dcsf.gov.uk/skillsstrategy/uploads/documents/21st\%20Century\%20Skills .pdf (Accessed: 20 January 2009).

Edwards, G. (2005) Connecting PDP to employer need and the world of work. HEA. Available at: http://www.heacademy.ac.uk/assets/York/documents/resources/resourcedatabase/i d71 connecting pdp to employer needs.pdf (Accessed: 9 April 2010).

Egan, J. (2004) Skills for sustainable communities. Available at: http://www.communities.gov.uk/publications/communities/eganreview (Accessed: 30 November 2008).

Gibbons, M., Limoges, C., Nowotny, H.,Schwartzman,S., Scott,P.,Trow,M. (1994) The new production of knowledge: the dynamics of science and research in contemporary societies. London: Sage. 
Harrison, R. (2005) Learning and development. London: Chartered Institute of Personnel and Development.

HEA (2008) Work-based learning. Workforce development: connections, frameworks and processes. Available at:

http://www.heacademy.ac.uk/assets/York/documents/workforce development.pdf (Accessed: 9 April 2010).

Knight, P. and Yorke, M. (2004) Learning, curriculum and employability in higher education. London: RoutledgeFalmer.

Lewis, S., Passmore, J. and Cantore, S. (2008) Appreciative Inquiry for change management. London: Kogan Page.

Little, B. and Esect Colleagues (2005) 'Employability and work-based learning', Learning and Employability, Series One, Esect/HEA [Online]. Available at: http://www.heacademy.ac.uk/assets/York/documents/ourwork/tla/employability/id11 4_employability_and_work-based_learning_591.pdf (Accessed: 28 May 2009).

Peters, J., Burkinshaw, S., Hughes, P., Keenan, C., Kumar, A. and Ward, R. (2009) 'Building research capacity in a practitioner network: the National Action Research Network on researching and evaluating Personal Development Planning and ePortfolio', Assessment, Learning and Teaching Journal (Leeds Metropolitan University), 5 (Spring), pp. 23-25.

Quality Assurance Agency for Higher Education (QAA) (2001) Guidelines for HE progress files. Available at: http://www.qaa.ac.uk/academicinfrastructure/progressfiles/guidelines/progfile2001.p df (Accessed: 30 November 2008).

Reed, J. (2007) Appreciative Inquiry: research for change. London: Sage.

Savory, J. (2008) 'An evaluation of the impact of embedding personal development planning', in O'Doherty, E. (ed) Papers from the fourth education in a changing 
environment international conference. California: Informing Science Press,pp.263282.

Senge, P. (1990) The fifth discipline: the art and practice of the learning organisation. London: Random House.

Soltani, E., Van Der Meer, R.B., Gennard, F. and Williams, M.T. (2004) 'Have TQM organisations adjusted their performance management (appraisal) systems? A study of UK-based TQM-driven organisations', The TQM Magazine, 16(6), pp. 403417.

Trowler, P. (2006) 'Teaching and learning regimes in higher education: illuminating enhancement efforts', Education in a Changing Environment Conference. University of Salford 12-13 January.

Walsh, A. (2008) 'What is distinctive about work-based knowledge and learning?', in Workbased learning. Workforce development: connections, frameworks and processes. HEA, p.8-17 [Online]. Available at:

http://www.heacademy.ac.uk/assets/York/documents/workforce development.pdf (Accessed: 30 November 2009).

Wedgewood, M. (2007) Employer engagement: higher education for theworkforce. Barriers and Facilitators - the results of a survey for the DfES. London: Department for Education and Skills.

Yorke, M. and Harvey, L. (2005) 'Graduate attributes and their development', New Directions for Institutional Research, Vol 2005 (128), pp. 41-58 [Online]. Available at: http://www3.interscience.wiley.com/journal/112221264/issue (Accessed: 30 June 2010).

Yorke, M. (ed.) (2009) Personal development planning and employability (revised edition).York: HEA [Online]. Available at: http://www.heacademy.ac.uk/assets/York/documents/ourwork/employability/PDP a nd employability Jan 2009.pdf (Accessed: 27 May 2009). 


\section{Author details}

Julie Savory is the Research Project Leader and is a Senior Lecturer in Housing and Regeneration at the University of Salford. Julie is also the Faculty PDP Co-ordinator and is Programme Leader for the FdSc Housing Practice (i.savory@salford.ac.uk).

Carole Conroy is a Senior Lecturer in Occupational Safety and Health at the University of Salford and is Programme Leader for the MSc Occupational Safety and Health.

Donna Berwick is the Skills and Recognition Team Manager and Student Life Directorate at the University of Salford. 